\title{
MÉTODOS VISUAIS SOB A PERSPECTIVA \\ DE KRUMM: A PROPOSTA DOS RETRATOS LINGUÍSTICOS
}

Mariana Kuhlmann Mestre em Filologia e Língua Portuguesa pela Universidade de São Paulo (USP) mariana_kuhlmann23@hotmail.com

\section{RESUMO}

O diálogo interdisciplinar empreendido na análise de contextos migratórios consiste em um pressuposto de valor inestimável que viabiliza uma aproximação com a diversidade linguística e cultural dos deslocamentos humanos. O estudo que se apresenta assume como fundamento matriz a necessidade de buscar encaminhamentos metodológicos que estejam alinhados com tal conduta interdisciplinar. Por essa razão, será abordada a proposta de Krumm e o seu modelo de retratos linguísticos. Para contextualizar a discussão proposta, iremos discorrer sobre as práticas de Sensibilização Linguística no contexto de ensino de línguas.

Palavras-chave: retratos linguísticos, sensibilização linguística, tolerância.

\section{ABSTRACT}

The interdisciplinary dialogue undertaken in the analysis of migratory contexts consists of a valuable prerequisite that makes possible an approximation with the linguistic and cultural diversity of human displacements. This study is based on the need to seek methodological guidelines that are coherent with such an interdisciplinary conduct. For this reason, we will approach Krumm's proposal and his model of linguistic. In order to contextualize the proposed discussion, we will discuss the practices of Linguistic Sensitivity and Tolerance.

Keywords: linguistic portraits, linguistic sensitivity, tolerance. 


\section{Introdução}

Transpor fronteiras em diferentes contextos de deslocamento constitui uma experiência que conduz o sujeito a questionar e a reconhecer a dinamicidade dos referenciais culturais e linguísticos que fundamentam as nossas identidades. Sob o crivo da incerteza que caracteriza a situação de partir e deixar seu país de origem, o migrante percorre caminhos linguísticos de uma língua outra.

Enquadrar essa condição do migrante e as intempéries enfrentadas no processo de aquisição de línguas incita o pesquisador a ampliar seus horizontes teóricometodológicos em busca de orientações que superem uma abordagem exclusivamente textual da experiência de aprender línguas. O sujeito, circunscrito em sua historicidade, deve ser contemplado como agente de travessias que não são apenas físicas, mas também psicossociais e linguísticas.

O presente artigo assume essa proposta de estudo e pretende realizar uma incursão no domínio dos métodos visuais empregados com o propósito de abordar fenômenos linguísticos. Inicialmente, proporemos uma reflexão acerca de condutas de mera tolerância linguística e cultural que são verificadas em contextos de plurilinguismo como figuram os contextos de migração. A partir desse levantamento, nos engajaremos em evidenciar a importância que reveste as denominadas práticas de Sensibilização Linguística com vistas a contextualizar o espaço de discussão em que métodos visuais, sobretudo a proposta de Krumm (2001), se situam. Por fim, nos ateremos ao modelo dos retratos e biografias linguísticas e suas possíveis reverberações no âmbito dos estudos centrados em processos identitários e aprendizagem de línguas outras. 


\section{O desenhar de um outro método}

A constante reconfiguração do espaço social decorrente dos movimentos migratórios resulta em contextos em que as diversidades linguística e cultural entremeiam as relações entre os sujeitos. A depender de como tal diversidade se configura e de como ela é enfocada em uma dada sociedade, pode haver condutas de resistência ao diálogo que impossibilitam, no contexto dos deslocamentos humanos, a integração social de grupos minoritários. Nesse caso, a diversidade passa a ser considerada um problema a ser tolerado, ou, em casos extremos, combatido.

A tolerância, enquanto prática social que pauta a coexistência entre diferentes grupos deve ser tratada com cautela justamente por aparentar ser uma prática que promove a aceitação não belicosa da diversidade linguístico-cultural. No entanto, o que se observa é que a tolerância é uma prática que não ultrapassa os limites da mera coexistência, não estimula o diálogo e, sobretudo, a convivência, conforme Lopes (2012) constata. Para a autora, a tolerância não promove inclusão social e, por essa razão, não fomenta nem a interação entre grupos sociais, nem a inclusão de grupos sociais minoritários.

Lopes (2012, p. 79) ainda afirma que essa dinâmica fundamentada em práticas de tolerar e coexistir é nociva, uma vez que "tolerar não necessariamente significa respeitar: a tolerância pode ser apenas um ato de indiferença, podendo chegar a ser uma espécie de gentil não-respeito". Para a autora, a tolerância apresenta restrições preocupantes, já que a construção de um Estado democrático demanda não somente a preservação das diversidades, mas também a garantia dos direitos e deveres de todos os sujeitos da sociedade - sejam eles migrantes ou não. 
No entanto, a tolerância apresenta limitações. A construção de um Estado democrático exige não apenas o reconhecimento e proteção de sua diversidade cultural, mas também a implementação de mecanismos espaciais capazes de garantir às minorias o pleno exercício de seus direitos fundamentais. Depois de tudo, o Estado não deve apenas garantir a coexistência, mas também assegurar a convivência entre todos os membros da sociedade (LOPES, 2012, p. 72).

O problema político da tolerância direcionada aos grupos minoritários no contexto dos deslocamentos humanos deve ser assumido pelos estudos que discutem o ensino de línguas em contextos plurilíngues. Parece ser inviável, sobretudo da perspectiva docente, somente tolerar os diferentes falares e as heranças linguísticas que compõem as dinâmicas estabelecidas em sala de aula. Essa tendência acaba por acirrar as tensões decorrentes da diversidade cultural, além de ser reducionista, uma vez que ignora a complexidade da dimensão psicossocial própria de uma experiência de ensino e aprendizagem de língua estrangeira. Sobre a complexidade implicada no enquadramento desse cenário culturalmente diverso e impassível de ser meramente tolerado, LimaHernandes e Ciocchi-Sassi (2015) apresentam as seguintes considerações:

Para compreender melhor esse novo enquadramento, poderíamos considerar espaços multiculturais diversos como aquarelas em que comunidades culturalmente diversas convivem a meias paredes com outras comunidades muito diversas, inclusive na língua, sem que a divisão espacial seja capaz de recortar grupos e laços de identidade de modo simples (LIMA-HERNANDES; CIOCCHI-SASSI, 2015, p. 105).

Ao tratar desses espaços plurais, Coelho e Simões (2017) explanam a proposta da Sensibilização Linguística. A partir dessa proposta, é possível compreender que, para superar as limitações impostas pela tolerância e consequentemente promover a 
integração de segmentos da sociedade que são linguística e culturalmente marginalizados, é preciso estimular a reflexão dos falantes acerca das línguas que são faladas em seu entorno social.

Assim, a Sensibilização Linguística consiste em uma prática de ensino que estimula a autoanálise do sujeito, de modo a contemplar competências plurilíngues e pluriculturais e a promover a conscientização acerca das suas próprias referências culturais e das referências daqueles com quem ele convive. Conforme Coelho e Simões (2017, p. 32) destacam, o enfoque da Sensibilização Linguística é justamente "[...] sensibilizar os alunos/indivíduos em geral para a existência de diversidade linguística e, por conseguinte, serve como suporte à aprendizagem de novas línguas".

É de suma importância ressaltar ainda que a Sensibilização Linguística, justamente por se adequar a diferentes experiências linguísticas e por apresentar a proposta de incentivar a reflexão linguística, não consiste em um conjunto de práticas estanques; ela se orienta pelos meandros particulares das referências culturais e linguísticas do sujeito, sendo tão dinâmica quanto instável. Contudo, isso não a torna inalcançável em termos teórico-metodológicos, principalmente quando assumimos a noção de imagens linguísticas.

A princípio, as imagens linguísticas são cruciais para a Sensibilização Linguística, pois é por meio delas que se perfazem os processos de reflexão linguística.

Coelho e Simões (2017), ao se debruçarem sobre as práticas de Sensibilização Linguística, afirmam que as imagens linguísticas consistem de uma construção coletiva e social composta por processos históricos, socioidentitários, cognitivos e discursivos próprios de cada sujeito ou grupo: 
[...] a imagem de uma língua é construída socialmente, através de processos dinâmicos, evolutivos, criados por indivíduos e/ou grupos sociais, de acordo com as suas histórias pessoais e vivências. Assim, as imagens têm como função manifestar e explicar os comportamentos individuais e sociais, orientar esses comportamentos e esclarecer as suas características socio-afetivas. Partindo do desempenho destas funções, as imagens podem influenciar os comportamentos dos sujeitos face ao Outro, à sua língua, podendo dificultar ou facilitar as relações interculturais (COELHO; SIMÕES, 2017, p. 34).

As imagens, nesse espaço de análise, assumem a função de orientar os sujeitos em relação por meio de atribuições positivas ou negativas direcionadas a uma língua e a todas as referências culturais vinculadas a ela. Em um primeiro momento, pode-se considerar essa imagem como um conjunto de valores que o sujeito sustenta sobre uma determinada língua e que, por essa razão, a representa. Porém, cabe ainda observar que a complexidade da imagem ultrapassa o domínio meramente "opinativo" e fica sujeita a uma série de fatores que afetam a sua configuração, como o "[...] contexto onde os indivíduos se inserem, a forma como se contatam e as fontes das representações" (COELHO; SIMÕES, 2017, p. 35).

Ao assumirmos esse rol de considerações, a questão metodológica de como apreender essas imagens, seja enquanto pesquisador, seja enquanto docente, se coloca com imponência na presente discussão. Torna-se pertinente, então, discorrer sobre os denominados "métodos visuais".

\subsection{Métodos visuais: uma breve discussão}

Nos estudos que visam à análise de fenômenos linguísticos predominam, conforme Melo-Pfeifer e Ferreira (2017, p. 131), a predominância do emprego de 
condutas metodológicas que prezam apenas pela coleta de dados tidos como essencialmente linguísticos, de modo a rejeitar - ou, ainda, a não dar a devida importância - a quaisquer outras informações que não sejam dessa natureza. Quando nos referimos a dados essencialmente linguísticos, estão implicados, por exemplo, as transcrições conversacionais e os corpora que reúnem coletâneas de textos.

É importante reforçar que não descartamos a importância de lidar com esses dados considerados essencialmente linguísticos. O que supomos nessa ocasião é que geralmente se faz necessário alargar o olhar a ser lançado a um dado fenômeno, de modo a buscar meios alternativos de elencar hipóteses. Desse modo, torna-se viável propor análises qualitativas que podem não se equilibrar necessariamente sobre as linhas de uma entrevista a ser transcrita, mas que podem ser produtivamente sustentadas por outros meios de obter dados de pesquisa.

No bojo dessa discussão emergem os métodos visuais. Os métodos visuais dialogam diretamente com a Sensibilização Linguística, e pode-se dizer que representam um movimento de resistência à tendência "lingualista" dos estudos linguísticos.

Com efeito, o recurso a métodos visuais desafia uma paisagem metodológica, epistemológica e heurística ainda marcada pela tendência "lingualista" (Block, 2014), que valoriza o texto e o discurso de entre todas as possíveis produções dos sujeitos, e coloca os investigadores diante do complexo semiótico que é o objeto visual, na sua multisemioticidade e multimodalidade, em que elementos verbais poderão ter um lugar, mas que terá que ser sempre interpretado, julgado e relativizado no seu diálogo com outros elementos (MELOPFEIFER; SIMÕES, 2017, p. 18).

Melo-Pfeifer e Simões (2017) afirmam que os métodos visuais consistem no emprego de desenhos, retratos, colagens, imagens e outras representações da mesma 
natureza que viabilizam uma possibilidade de acesso à dimensão cognitiva, afetiva e psicossocial dos fenômenos linguísticos. Além disso, trata-se de um conjunto de procedimentos que não se encontra totalmente estabilizado em termos científicos, mas que, ainda assim, oferece uma vasta gama de encaminhamentos de estudo.

Esses encaminhamentos de estudo, apesar de serem recentes no que concerne aos estudos linguísticos, já são empregados em outros campos de estudo como a psicologia analítica. Jung (2002), por exemplo, utilizava o método das mandalas e da confecção de aquarelas quando tratava seus pacientes. Para isso, ele apresentava uma figura circular - a mandala - e solicitava que o sujeito a colorisse com lápis de cor, giz de cera ou tintas de modo a representar a si mesmo. O autor acreditava que essa tarefa de reflexão auxiliava o paciente a extravasar, por meio de representações simbólicas e com cores e formas, os conflitos internalizados em sua subjetividade. Após essa tarefa, o sujeito teria condições de explicar discursivamente os impulsos que o levaram a se retratar desse modo.

Noutro trabalho intitulado "Um Estudo do Processo de Individuação" (vol. 9i), a individuação se expressa através de uma série de aquarelas feitas por uma mulher de meia-idade que estava sendo tratada por Jung. As pinturas sob a forma de mandalas, isto é, elas adotam formas circulares (representando a psique) contendo desenhos intricadamente equilibrados. Uma análise dos sucessivos desenhos conta a história do processo de individuação desta mulher. Jung observa que os pacientes reconhecem com frequência os efeitos tranquilizadores que obtêm traçando desenhos de mandala (HALL; NORDBY, 2018, p. 73).

Colorir as mandalas é, então, para a psicologia analítica, uma atividade motora que ativa tanto as funções cognitivas quanto as funções psicoafetivas do sujeito e permite com que ele organize eventuais experiências traumáticas. A partir dessa atividade, ainda 
é possível expressar concretamente o que está imerso em uma dimensão abstrata da subjetividade, como afetos e lembranças. No caso dos métodos visuais, as atividades apresentadas ao sujeito fazem com que as cores, formas, desenhos, colagens, vídeos e outras representações expressem concretamente as relações simbólicas abstratas presentes em sua realidade linguística.

Para melhor ilustrar os resultados proporcionados por esses métodos, cabe citar alguns trabalhos recentes que demonstram o alcance dessa proposta de estudo.

Piippo e Espada (2017) solicitaram a adultos e crianças residentes na cidade de Helsinque e aprendizes de língua portuguesa na modalidade de língua de herança que desenhassem tudo aquilo que remetesse a Portugal e ao Brasil. Ao conformaram a coleta de dados nessa tarefa de desenhar, o estudo das autoras lida com elementos icônicos para acessar atitudes e imagens linguísticas e, assim, investigar quais são as inclinações ou ressalvas do sujeito ao falar a língua portuguesa.

Outro estudo que se assemelha a esse escopo de análise é o de Simões (2017). A pesquisadora também emprega a confecção de desenhos para coletar seus dados, mas seu foco consiste em apreender as particularidades do processo de aprendizagem de adolescentes falantes maternos da língua portuguesa, em face da aquisição do inglês como língua estrangeira e com vistas a constatar que "[...] o desenho permite o sujeito projetar-se no irreal, no virtual e imaginário sem ser julgado ao mesmo tempo que pode representar o universo de referência e de percepção das relações sociais dos indivíduos, mais ou menos estereotipado" (SIMÕES, 2017, p. 39).

Já Silva (2017) nos apresenta um estudo que também é pautado nos métodos visuais, mas não utiliza desenhos. Os dados foram obtidos por meio de histórias digitais produzidas por luso-descendentes residentes na Alemanha. Como o próprio nome já 
sugere, as histórias digitais consistem na disposição de imagens produzidas no computador, criadas individualmente por cada participante da pesquisa. O objetivo dessa tarefa é fazer com que o sujeito retrate as suas identidades linguísticas por meio da conscientização acerca de suas origens culturais. Para "construir" essa história, Simões (2017) sugeriu que entrevistas com familiares, músicas, fotos e peças decorativas relacionadas a Portugal fossem apresentadas no formato de vídeo, com a finalidade de ordenar uma narrativa sobre as referências familiares do sujeito.

Seguindo a mesma tendência, Melo-Pfeifer e Ferreira (2017) coletam seus dados que também envolvem luso-descendentes residentes na Alemanha - por meio de tarefas propostas em sala de aula e centradas no conceito de narrativas. Aos alunos foi solicitado que eles desenhassem a si próprios ao falarem português. Paralelamente, eles deveriam elaborar breves narrativas, orais e escritas, que explicassem as razões que os levaram a optar por certos recursos icônicos. Essas etapas de pesquisa foram orientadas de modo a fomentar a reflexão linguística do sujeito sobre a sua identidade e o seu processo de aprendizagem de língua portuguesa.

O modelo de Krumm (2003; 2010) nos oferece, assim como os demais estudos citados, importantes contributos sobre os métodos visuais e as suas possibilidades de aplicação e análise. A seguir, ateremo-nos a esse modelo com mais detalhes.

\section{O modelo de Krumm e as biografias linguísticas}

Revuz (2001, p. 220) afirma que "cada um tem uma história singular com a língua que fala". A autora, ao discorrer sobre os processos de aprendizagem de língua estrangeira, observa que cada falante sustenta uma narrativa de uso que está atrelada às 
suas línguas. Essa narrativa parece ser particularmente evidenciada principalmente quando o falante está engajado em aprender uma outra língua. Isso porque, ao entrar em contato com uma língua estrangeira, os valores atrelados a sua língua materna são confrontados com outros valores. Essa experiência de confronto pode abalar perspectivas que aparentemente são estáveis, o que cria um contexto propício para que as narrativas de uso sejam reveladas.

A noção de biografia linguística é fundamental para o estudo de Krumm (2003), e por isso será necessário abordar tal conceito. Recorrendo a uma explanação sucinta, pode-se dizer que às línguas são atribuídos valores socioculturais e afetivos pelos usuários que interferem na condição do sujeito, enquanto falante, e, por conseguinte, sustentam o estatuto social da língua. A relação entre tais valores e a condição do sujeito é passível de ser organizada em uma modalidade de narrativa veiculada por certos exercícios de reflexão linguística, previstos na proposta dos métodos visuais e que esclarecem o que condiciona o emprego ou rejeição de uma língua.

A título de exemplificação, cabe mencionar a situação de muitos filhos de famílias que se encontram refugiadas. Muitos deles, nascidos no Brasil, conviverão com a língua portuguesa e com as línguas maternas de seus pais. Esse sujeito, nessas condições, poderá ser linguisticamente competente em mais de uma língua. Entre as possíveis configurações dessa situação linguística, há de que as línguas maternas de seus pais se tornem as línguas dos aniversários, das canções de ninar, das reprimendas, das rezas, das brigas entre irmãos. Já a língua portuguesa pode se tornar a língua da escola, das amizades fora de casa, das brincadeiras no recreio, da lição de casa. 
Os valores atribuídos às línguas são conformados no âmbito dessas experiências e, assim, o sujeito poderá associar certas histórias de vida a eles. Desse processo, emergem as narrativas de uso da língua, também compreendidas como biografias linguísticas.

Melo-Pfeifer e Ferreira (2017) abordam as biografias linguísticas em termos de narrativas de uso. Para as autoras, em contextos de superdiversidade, as narrativas de vidas linguísticas ou biografias linguísticas assumem particular importância, uma vez que

[...] podem fornecer ocasiões de focalização do sujeito sobre aspectos como os condicionantes sociolinguísticos da sua biografia e da sua relação com outros sujeitos, a relação de poder entre as línguas do/no seu repertório e as micropolíticas linguísticas individuais ou familiares. Essas narrativas abrem, por isso, espaços de reflexão e de conscientização acerca do plurilinguismo individual e do multilinguismo societal (...). (MELO-PFEIFER; FERREIRA, 2017, p. 134).

\subsection{Retratos linguísticos: uma incursão teórica}

O texto de Krumm (2003) que discutiremos nessa ocasião apresenta a proposta dos retratos linguísticos por meio de dados produzidos por crianças de 7 a 14 anos residentes em países de língua alemã. Originalmente escrito em alemão, uma vez que o autor é austríaco, o texto "Minha barriga é italiana... Crianças falando sobre línguas" foi traduzido em uma versão livre para o português para que pudéssemos cotejá-lo com os conceitos que alinhavamos anteriormente.

O autor parte do princípio de que as crianças desenvolvem desde cedo um senso apurado referente à identificação de diferenças linguísticas. Esse senso apurado é denominado consciência linguística e parece ser particularmente estimulado no caso de 
crianças que convivem em ambientes multilíngues. Essa realidade linguística diversa não deve ser ignorada pelas escolas e pelas políticas linguísticas.

Há uma considerável preocupação do autor com os filhos de migrantes; conforme ele relata, algumas dessas crianças tiveram experiências traumáticas e negativas em relação às suas línguas maternas ou às línguas maternas dos seus pais. Isso vale principalmente para "os filhos de migrantes que foram proibidos de dizer que a sua língua materna é o curdo e vale também para crianças que foram caçoadas em razão da variedade linguística que falam"i (KRUMM, 2003, p. 110).

Baseada nessas constatações, a tarefa dos retratos linguísticos é aparentemente simples. Concebida a princípio como uma atividade escolar a ser realizada em caráter voluntário, ela consiste na distribuição de silhuetas", contornos de corpos, que devem ser preenchidos e coloridos individualmente de modo a representar as línguas que são (re)conhecidas pelos participantes.

Figura 1 - Sugestão de silhueta proposta por Krumm e seu estudo sobre retratos linguísticos

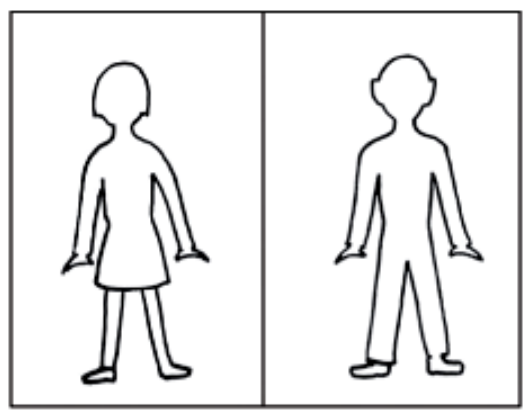

Fonte: KRUMM, 2010.

Krumm (2003) é categórico e afirma que o pesquisador ou professor que conduz essa tarefa não deve interferir em como o sujeito deverá se expressar no decorrer da atividade. A eficiência dos retratos linguísticos como uma ferramenta de rastreio das 
biografias linguísticas é orientada pelo engajamento voluntário daqueles que os confeccionam. Para o sujeito, a atividade deve ser realizada, na medida do possível, a partir de suas relações afetivas e psicossociais e não de orientações normativas.

Não deve haver diretrizes sobre como as línguas serão pintadas no corpo, inclusive se a criança deve dizer ou escrever algo. Quando as crianças quiserem e puderem descrever os seus retratos, elas certamente estão autorizadas a fazê-lo. A minha experiência indica que elas o fazem de bom grado durante a atividade. Além disso, nada deve ser comentado sobre o quão bem se deve falar uma língua para que ela seja retratada no desenho. Aqui os professores devem se expressar discretamente e vagamente: todas as línguas que vocês conhecem e que vocês conseguem falar algo podem ser representadas. É importante que as crianças expressem as percepções sobre "suas línguas" e não se sintam impedidas por meio de diretrizes normativas 111).

A produção dos retratos linguísticos estimula o sujeito a representar simbolicamente os valores linguísticos atribuídos às línguas que ele fala, independentemente dos níveis de competência linguística. Trata-se de um exercício de reflexão linguística que permite revelar valores linguísticos que podem ficar encobertos no discurso e possibilita, ainda, a expressão em uma dimensão concreta, o que muitas vezes permanece silenciado e inacessível na subjetividade dos falantes.

Em termos metodológicos, é importante que o falante que confeccionou o retrato linguístico em questão tenha a oportunidade de descrevê-lo para o grupo ou para o pesquisador, caso esteja disposto a isso. É justamente nesse momento que se torna possível entrar em contato com as biografias linguísticas, uma vez que o sujeito narra, em termos de uso linguístico, e concretiza no discurso aquilo que foi colorido e representado no retrato. Segundo Krumm (2003, p. 111), “nessa ocasião muitos conflitos linguísticos, 
histórias de migração, mas também preferências pessoais e medos linguísticos vêm à tona"iv.

O processo das biografias linguísticas é orientado pela correlação entre a representação das línguas, as cores empregadas para representá-las e os lugares que foram preenchidos com a finalidade de representá-las. Para Krumm (2003), parece haver uma relação simbólica entre os valores atribuídos às línguas e o lugar onde ela foi situada no retrato. É como se a configuração dos retratos nos fornecesse pistas a serem rastreadas nos depoimentos coletados posteriormente.

O caráter consideravelmente lúdico da atividade nos permite mobilizar a imagem da brincadeira de ligar os pontos para explanar como se dá o processo de revelação das biografias linguísticas. Ao confeccionar os retratos linguísticos, o sujeito distribui a sua realidade linguística pela silhueta. Essa distribuição seria os pontos da brincadeira. $\mathrm{Na}$ ocasião em que o sujeito se engaja na descrição dessa distribuição, ocorre a ligação dos pontos de modo a compor a sua biografia linguística.

É necessário que alguns dados discutidos por Krumm (2003) em seu estudo sejam apresentados de modo a ilustrar o seu modelo e a nos amparar nessa incursão teórica. Em seu texto original, o autor disponibiliza apenas as biografias linguísticas produzidas pelos participantes de seu estudo; os retratos linguísticos são descritos a partir delas e não há disponibilização de suas imagens na versão original do artigo.

O primeiro dado que gostaríamos de apresentar é o depoimento de Jogie, de 11 anos, descendente de nigerianos e residente em país de língua alemã.

Para mim, o Yoruba está no corpo, porque o corpo não consegue ouvir e eu não consigo entender muito bem Yoruba. $O$ inglês está na cabeça, porque eu às vezes tenho que concentrar muito para memorizar as 
palavras. O francês está para mim nas pernas, porque ele (o francês) fica muito longe de mim e é difícil de aprender certo apesar de eu desejar isso. E para ir longe, é preciso ter pernas. ${ }^{v}$

Sua biografia linguística é forjada entre o yoruba, o inglês e o francês e, apesar de Yogie residir em um país de língua alemã, ele não menciona o alemão em seu depoimento. O yoruba ocupa, nitidamente, uma posição de destaque, uma vez é representado no corpo apesar de ser uma língua na qual ele declara não ser linguisticamente competente. Nesse caso, há uma dissociação entre o elemento afetivo e a competência linguística do falante, uma vez que houve o interesse em representar uma língua que ele não domina. As relações abstratas que constam em seu retrato também nos informam acerca das dificuldades por ele enfrentadas no aprendizado do inglês e do francês.

O retrato de Ferenc, 12 anos, descendente de húngaros e italianos, e também residente em um país de língua alemã, por sua vez, também nos fornece dados consistentes sobre as biografias linguísticas e os índices de corporeidade.

O meu coração é húngaro. As partes mais importantes do meu corpo são húngaras. A minha barriga é italiana, porque eu gosto de comer comida italiana. Minhas pernas são alemãs, porque eu vivo em uma região onde se fala alemão.

Ferenc expressa o seu vínculo afetivo com o húngaro ao situar essa língua no coração e nas partes por ele consideradas as mais importantes em seu corpo. Suas preferências pessoais não escapam aos retratos e nos concede dados tanto sobre a subjetividade do falante quanto sobre as suas referências culturais. O modo como ele se situa geograficamente no atual momento também indica como ele se situa 
linguisticamente, uma vez que ele assume que suas pernas são alemãs. Isso denota que há uma identificação do sujeito com a língua.

Por fim, Ebi, 10 anos, nascido no Irã e residente em um país de língua alemã, nos evidencia por meio de seu retrato linguístico as relações simbólicas e as referências culturais presentes em sua realidade linguística.

Inglês tem a cor verde, porque lá sempre chove. Árabe tem a cor marrom, porque os países árabes têm muitos desertos. Alemão tem a cor preta, porque alemão é difícil. Persa tem a cor azul, porque lá o céu é muito bonito. ${ }^{\text {vi }}$

Quatro línguas constam representadas em sua biografia linguística: o inglês, o árabe, o alemão e o persa. Iraniano, Ebi tem como línguas maternas o árabe e o persa, línguas às quais são atribuídos valores aparentemente positivos e associados ao seu espaço geográfico de nascença. A representação da língua inglesa se dá do mesmo modo. Já o alemão, língua estrangeira por ele aprendida em seu atual país de residência, é representado de modo a narrar as dificuldades por ele enfrentadas em seu processo de aprendizagem.

\section{Considerações finais}

A partir das tensões que entremeiam o contexto dos deslocamentos humanos, surge a necessidade de discutir as limitações que se presentificam no discurso da tolerância. O ato de tolerar, por não incentivar de modo efetivo o diálogo e por considerar as diversidades culturais como um problema a ser combatido, acaba por lançar 
as línguas dos falantes que se encontram na condição de migrantes ou refugiados às margens de uma suposta identidade nacional do país para onde migraram.

Esse cenário nos conduz a reconhecer a necessidade de promover práticas de Sensibilização Linguística. Entre essas práticas há a proposta dos métodos visuais como encaminhamento metodológico possível.

No artigo apresentado nessa ocasião, optamos por discutir a proposta de Krumm (2003, 2010) e a sua abordagem de análise linguística pautada nos métodos visuais. Ao recomendar a coleta de dados por meio de retratos linguísticos alinhados a depoimentos orais ou escritos, tal abordagem nos evidencia as particularidades que estão implicadas na subjetividade de sujeitos bilíngues ou plurilíngues. É notável que os retratos linguísticos consistem em uma via de acesso que nos conduz até a valoração afetiva que o falante atribui às suas línguas.

Por detrás de dados quantitativos recolhidos no âmbito das entrevistas ou de questionários estruturados ou pré-estrurados, pode haver também outras línguas que o falante, por questões sociais, política e culturais declara não falar. Em contrapartida, a não declaração não implica, necessariamente, que essa língua não seja falada em seu cotidiano. A simples tarefa de colorir silhuetas e descrevê-las nos permite apreender essas dissonâncias entre o que é declarado e o que o sujeito efetivamente reconhece.

A aplicação dos métodos visuais encontra-se em ebulição. Estabelecer e seguir trajetos de pesquisa seguindo a proposta de Krumm (2003), por exemplo, é uma tarefa cujo escopo consiste em analisar identidades linguísticas, mas que demanda uma investigação interdisciplinar. Muitas das questões postuladas e os dados coletados dialogam com outras áreas de conhecimento, como a psicologia e as ciências sociais. 
Igualmente relevante é o modo de apreender e compreender identidades proporcionado pelos retratos linguísticos. Ao conciliar uma tarefa de confeccionar os retratos à coleta de depoimentos, o falante assume o seu espaço enquanto sujeito que estabelece relações simbólicas, instáveis e dinâmicas com as línguas. O fator psicoafetivo do uso linguístico norteia as análises krummianas o que revela a condição e a história pessoal dos falantes que há por detrás dos dados recolhidos.

As informações fornecidas pelas representações constantes nos retratos linguísticos não devem ser assumidas meramente como um enquadramento que engessa a dinamicidade das identidades. Os dados por eles fornecidos, pelo contrário, devem ser contextualizados e tomados como registros da diversidade linguística que marca a subjetividade do sujeito em um dado momento. Portanto, pode-se dizer que esses dados ultrapassam os contornos das silhuetas linguísticas e nos conduzem pelas particularidades que permeiam uma condição social fundamentada na diversidade linguística.

\section{Referências}

COELHO, Mafalda; SIMÕES, Ana Raquel. As imagens das línguas de alunos do 20 ciclo básico: foco nas línguas curriculares. In: MELO-PFEIFER, S.; SIMÕES, A. R. (eds.).

Plurilinguismo vivido, plurilinguismo desenhado: estudos sobre a relação dos sujeitos com as línguas. Santarém: Instituto Politécnico de Santarém, 2017. p. 31-54.

HALL, Calvin; NORDBY, Vernon. Introdução à Psicologia Jungiana. Tradução Heloysa de Lima Dantas. São Paulo: Cultrix, 2014.

JUNG, Carl Gustav. Os arquétipos e o inconsciente coletivo. Tradução Dora Mariana Ferreira da Silva. Petrópolis, RJ: Vozes, 2002.

KRUMM, Hans Jürgen. Mehrsprachigkeit in Sprachenporträts und Sprachenbiographien von Migrantinnen und Migranten. Der Arbeitskreis Deutsch als

Fremdsprache/Zweitsprache Rundbrief. Jena: AkDaf, v. 61, p. 16-24, 2010. 
Mein Bauch ist italienisch. In: BAUMGARTEN, N.; BÖTTGER, C.; MOTZ, M.; PROBST, J. (eds.). Übersetzen, interkulturelle Kommunikation, Spracherwerb und Sprachvermittlung - das Leben mit mehreren Sprachen. Bochum: AKS-Verlag, 2003. p. 110-114.

LIMA-HERNANDES, Maria Célia; CIOCCHI-SASSI, Karina. Língua de herança como integradora de identidades. In: JENNINGS-WINTERLE, F.; LIMA-HERNANDES, M. C. Português como língua de herança: a filosofia do começo, meio e fim. Nova York: BEM, 2015. p. 104-115.

LOPES, Ana Maria Dávila. Da coexistência à convivência com o outro: entre o multiculturalismo e a interculturalidade. Revista História Oral. Rio de Janeiro: Associação Brasileira de História Oral, v. 14, p. 97-122, 2012.

MELO-PFEIFER, Sílvia; FERREIRA, Teresa. Diz-me lá o que é que tu desenhaste aqui - das narrativas visuais a uma intertextualidade multimodal? In: MELO-PFEIFER, S.; SIMÕES, A. R. (eds.). Plurilinguismo vivido, plurilinguismo desenhado: estudos sobre a relação dos sujeitos com as línguas. Santarém: Universität Hamburg, Universidade de Aveiro, 2017. p. 129-155.

PIIPPO, Jarna; ESPADA, Francisco Mira. Futebol, pastéis e castelos de areia - como diversificar as imagens da lusofonia? In: MELO-PFEIFER, S.; SIMÕES, A. R.

(eds.). Plurilinguismo vivido, plurilinguismo desenhado: estudos sobre a relação dos sujeitos com as línguas. Santarém: Universität Hamburg, Universidade de Aveiro, 2017. p. 57-82.

REVUZ, Christine. A língua estrangeira entre o desejo de um outro lugar e o risco do exílio. Trad. Silvane Serrani-Infanti. In: SIGNORI, I. (ed.). Lingua(gem) e identidade: elementos para uma discussão no campo aplicado. Campinas: Mercado de Letras, 2001. p. 213-230.

SILVA, Fátima. Uso das histórias digitais na compreensão da identidade dos alunos lusodescententes na Alemanha. In: MELO-PFEIFER, S.; SIMÕES, A. R. (eds.). Plurilinguismo vivido, plurilinguismo desenhado: estudos sobre a relação dos sujeitos com as línguas. Santarém: Universität Hamburg, Universidade de Aveiro, 2017. p. 105-128.

Recebido em 15 de setembro de 2018. Aceite em 13 de fevereiro de 2019.

\footnotetext{
i "Manche Kinder haben eventuell schon schlechte Erfahrungen mit ihren Sprachen gemacht - das gilt für Migrantenkinder, die nicht überall erzählen durften, dass ihre Muttersprache Kurdisch ist, das gilt aber auch für Kinder die wegen ihres Dialekts gemahnt werden."
} 
ï O termo original em alemão é "Silhouetten".

iii "Es sollten keinerlei Vorgaben gegeben werden, wie die Sprachen in den Körper gemalt werden, auch nicht, ob etwas dazu zu sagen oder schreiben ist. Wenn Kinder ihre Porträts beschriften wollen (und können), so dürfen sie das natürlich. Meine Erfahrung ist, dass sie durchweg gerne tun. Auch sollte gar nicht angesprochen werden, wie gut man eine Sprache können muss, um sie einzumalen. Die Lehrenden sollten sich hier ruhig etwas vage ausdrücken: alle Sprachen, die ihr kennt, von denen ihr etwas könnt. Es ist wichtig, dass die Kinder ihre Gedanken zu "ihren Sprachen" äußern und nicht durch normative Vorgaben daran gehindert warden."

iv "Dabei kommen vielfach Sprachkonflikte, Migrationsgeschichten, aber auch die persönlichen Vorlieben und (Sprachlern-)Ängste zum Ausdruck."

$\checkmark$ "Yoruba ist bei mi rim Körper, weil der Körper nicht hören kann und ich kann Yoruba nicht so gut verstehen. Englisch ist bei mi rim Kopf, weil ich mich manchmal ziemlich konzentrieren muss um mir Vokabeln zu merken. Französisch ist bei mir in den Beinen, weil es für mich sehr fern liegt es richtig zu lernen obwohl das mein Wunsch ist. Und um in die Ferne zu gehen muss man Beine haben."

vi "Englisch hat grüne Farbe, weil dort immer es regnet. Arabisch hat braune Farbe, weil arabische Länder viele Wüsten haben. Deutsch hat schwarze Farbe, weil Deutsch schwer ist. Persisch hat blau Farbe, weil dort schöne Himmel hat". 